Copy 1 


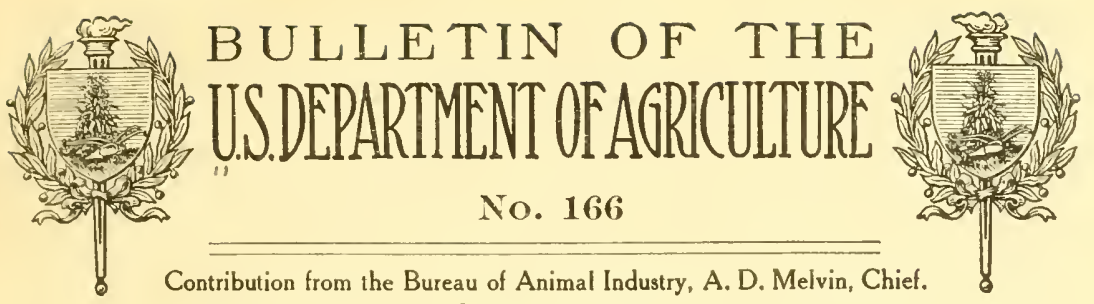

January 22, 1915.

(PROFESSIONAL PAPER.)

\section{OPHTHALMIC MALLEIN FOR THE DIAGNOSIS OF GLANDERS.}

By John R. Mohler, Assistant Chief of Bureal, and Adolph Eichноrn, Scnior Bacteriologist, Pathological Division.

\section{INTRODUCTION.}

It is no longer doubted that in the work of controlling glanders the destruction of the infected animals shou!d be given prompt consideration, and, if possible, the infection should be traced to its origin. Unfortunately, the nature of the disease is such that only a comparatirely small proportion of the cases can be recognized by the ordinary clinical examination, and as long as we limit our efforts to the destruction of these cases the disease will continue to spread. An effective control can be accomplished only by the elimination of all centers of infection of glanders. Therefore it is essential primarily to have a means of diagnosing accurately all forms of the disease.

Numerous publications have been issued on the various methods of dingnosis, and it seems that while some favor a certain method or methods, others appear to produce sufficient evidence to point out the inadequacy of these methods. There is no question that in the last decade important progress has been made in the diagnosis of this disease. Since the discovery of mallein, competent investigators have fruitfully studied this phase of the question of the control of glanders, and at the present time we possess several methods by which we are reasonably sure of diagnosing practically all cases of glanders. A minimum percentage of failures will probably always have to be contended with, as a good many factors enter into the execution of any test.

In judging a method which would be the most satisfactory for the diagnosis of glanders various things have to be taken into considera-

NoTE.-This bulletin points out the advantageous and satisfactory use of the ophthalmic mallein test in the diagnosis of glanders and the necessity for prompt action on reactors to this test in eradicating this disease. Of interest to veterinarians and state !ive-stock sanitary authorities.

$68247^{\circ}-15$

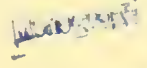


tion, but especially the reliability of the test. It should be convenient, the results should be manilested as early as possible, the reaction should be distinct and woll marked, and, probably the most important, of all, it should be possible for the practicing veterinarian to apply the test. 'The last condition must be serionsly considered, since the standing of the veterinarian in the rommmnity and the confidenee of the public in his work would be more manifest if in suspected cases he could personally decide on the diagnosis instead of haring to depend entirely on the results of serum tests made at some distant lisboratory.

\section{VARIOUS METHODS FOR DIAGNOSING GLANDERS.}

It would require a great amount of spake to enter into the history of the various methods of diagnosis and to enumerate the data we possess on the different tests. The advantages and disadvantages of the varions methods, esperially of the subcutaneous mallein tests, have been repeatedly published and are accessible to all those who are interested in the subject. There is no question that the subcutaneous mallein test is one of the valuable diagnostic agents for glanders, but no one ean any lenger deny that failures from this test are more mumerous than are desirable. As a mater of fact, the uncertainty of the results from this test calused numerous investigators to seck some other method which might replace the subcutameous mallein test. Besides the failures resulting from it, the technic of executing the test, together with the time required for its dotermination, make it umpopular with many voterimarians and sanitary officer's.

Of the other tests which from time to time have been devised for the cliagnosis of glanders, the precipitation, the opsonic, and the conglutination tests will not be considered, since the results obtained from them are not encouraging.

For laboratory tests the combined agghutination and complementfixation test will no doubt, remain the most satisfactory, and should always be applied in cases where doubt arises as to the results of other tests carried out by the practicing veterinarian. 'These latiter' should be considered as accessory tests and provision should be made "verywhere so that in case of doubt the serum conld be subjected bo the laboratory test mentioned, and the final decision should rest on its outeome.

\section{THE OPHTHALMIC MALLEIN TEST.}

During the last few years the ophthalmia: mallein test has gained great favor in the diagnosis of glanders. The popularity of the test is rapidly gaining wherever it has been applied, and among its supporters we find at the present time the greatest authorities on the 
subject of glanders and on clinieal diagnosis. 'This method of testing is at present officially reoognized in Austria, and the indieations are that ere long it will constitute the official test in other comntries. The results obtained in Austria, where the test has been cmployed for sereral years, are rery gratifying, and Prof. Schmurer, of that country, one of our greatest authorities on glandris, chims that the control of the disease can be very satisfactorily carricd out by the application of the cyc test, supplemented in doubtful ares by the agghtination test. Bavaria has recently adopted this method of diagnosis for official testing. In Germany the method is also gaining in favor, and current veterinary literature contains expressions of satisfaction with this test from many German authorities. In the United States the Bureau of Animal Industry, in consideration of the farorable results obtained, has recognized this method of diagnosis for interstate shipments of equines. The test has also been officially recognized by the Camadian authorities, and thus far no sanitary official connected with any of the States in this country has declined to approve this test.

The favorable results which have been obtained with this diagnostic: method can no longer be denied. Its practicability is apparent, and its use in the control of glanders appears to be now an absolute necessity.

\section{SIM PLICITY OF PROCEDURE.}

The ophthalmic test has a great adrantage orer others because of its rery simple application. It may be readily executed by ans veterinarian, and its other adrantages are that the results are obtained in a comparatively short time and are, as a rule, distinct and definite. The simplicity of its application is plainly manifest when compared to the subcutaneous test, as it is only necessary to drop two to three Irops of concentrated mallein into one of the eyes of the animal to be tested, or, by a still simpler procedure, to dip a camel's-hair brush into mallein and introduce this into the conjunctival sac of the animal. The reaction usually commences in five to six hours after the introduction of the mallein and lasts from 24 to 36 hours. A positive reaction is manifested by a purulent secretion from the tested rye. This may be very profuse or slight, sometimes associated with a severe conjunctivitis and edema of the lids, and at other times without any inflammatory symptoms being present. At times only a very small quantity of pus may be present in the immer canthus of the eye. At other times the reaction may manifest a true pyorrhea.

The reaction manifests itself in varying degrees in the animals, but the intensity of the reaction has no relation to the extent of the dis(ase in the reactor. 
RELIABILITY OF THE TEST.

The available data on the ophthalmic mallein test are sufficient to draw conclusions as to the reliability of the method, and in Austria alone it has been applied on many thousands of cases with uniformly good results.

In considering the good results obtained and the advantages of this method of testing, a concentrated mallein has been prepared for this purpose by the Bureau of Animal Industry, and this was made available to a number of practicing reterinarians who desired to gire this method of testing a thorough trial. It has also been employed by inspectors of the Bureau of Animal Industry in their field work, and reports are accessible regarding its action for diagnostic purposes on more than 18,000 cases. The results from all sources were uniformly satisfactory. Practicing reterinarians who have given this method a trial have reported very favorably on the results, and the tests conducted by the bureau inspectors on several thousand animals were also satisfactory. The method has been applied here in Washington whenerer possible, and recently in some immunizing tests of glanders conducted by the Bureau of Animal Industry there was a good opportunity to repeatedly employ this test. In all these instances the results were uniformly good. In cases of glanders there appeared a marked purulent conjunctivitis, and the reaction at times was so severe that the animal could not open its tested eye.

\section{BEST RESULTS WITH RAW MALLEIN.}

The essential factor in obtaining satisfactory results from the test appears to be in the use of the right kind of mallein. It must be by all means a concentrated mallein, and apparently the best results follow the use of raw mallein, which, as a rule, represents the mallein obtained after the concentration of the filtrate from the bouillon cultures of the glanders bacilli. The ordinary mallein used for subcutaneous testing is not adaptable, and the failures which have been reported in the literature were without doubt, in the majority of cases, due to the fact that the mallein employed was not sufficiently concentrated. Marioth ${ }^{1}$ correctly asserts that the reaction does not depend as much on the quality and quantity of the mallein as on its concentration. Our experiments in preserving such mallein with the ordinary quantity of 0.5 per cent carbolic acid showed that it does not interfere with the results of the test, although the lacrimation which follows immediately after the introduction of such mallein is more profuse than when earbolic acid has not been added, but this disappears within one or two hours after the application of the test.

\footnotetext{
1 Monatsh. f. prakt. Uerheilk., bd. 24, hft. 7/8, p. 340-373; hft. 9/10, p. 426-456. Stuttgart, 1913.
} 


\section{PREPARATION OF THE MALLEIN.}

The concentrated mallein which has been.used for our work and which gave such satisfactory results was prepared at the request of the authors by and in cooperation with Mr. A. M. West, of the Biochemic Division, as follows:

The media consists of bouillon containing 5 per cent glycerin, 1 per cent peptone, and 5 per cent $\mathrm{NaCl}$. The reaction is that of the natural acidity of the meat, no acid or alkali being added. The flasks of media are inoculated with virulent cultures of Bacillus mallei and placed in the incubator at $37.5^{\circ} \mathrm{C}$. for a period of two months or more. The stock cultures of $B$. mallei are kept on agar, and their virulence is renewed when necessary by passage through a series of guinea pigs.

The well-grown cultures show a heary mass of organisms, which generally sinks to the bottom of the flask. This grow th is of a whitish color splotched with brown. The cultures are then removed from the incubator and heated for one hour in the Arnolit sterilizer. Then they are stored for two weeks in a dark closet to settle. The clear liquid is then carefully decanted and the growth proper is discarded.

A measured amount of the decanted liquid is concentrated over a steam bath to one-third its volume. It is then filled into flasks and sterilized and again filtered while hot, first through one then through three paper filters. Next the clear liquid is passed through a Berkefeld filter. This is followed by a concentration to one-tenth its original volume and by sterilization.

To the raw mallein, concentrated to one-tenth its original volume, is added 0.5 per cent carbolic acid and 20 per cent glycerin. Then the liquid is again concentrated to one-tenth its original volume, filtered while hot through filter paper, and sterilized. It is kept in a dark place for a week, and if upon inspection a precipitate is found the mallein is again passed through paper filters and sterilized. The finished product is a clear, sirupy, dark-brown liquid; with a disagreeable odor. The mallein is then bottled, under aseptic conditions, in small vials and is ready for use.

It is advisable to provide the mallein for the tests in small vials, each containing about $1.5 \mathrm{c}$. c. of mallein, which is sufficient for testing 15 horses. After the vial has been opened and part of the contents used for testing, especially if the mallein has been taken out with a camel's-hair brush, the remainder should not be used for tests applied on subsequent days, but should be discarded.

\section{THE USE OF DRY MALLEIN.}

Another form of mallein which has been used quite extensively for the eye test is the mallein siccum, or dry mallein. This represents an alcoholic precipitate of mallein. It is a fine gray powder and must be dissolved in water before it is used. The solution loses its effectiveness in a very short time and must be prepared fresh on the day of the test. Dr. K. F. Meyer, formerly of the University of Pennsylvania and now of the University of California, has used the dry mallein extensirely, and at the present time this preparation is employed in Pennsylvania for the application of the ophthalmic test. For this purpose two vials are sent out from the laboratories of the Pennsylvania Livestock Sanitary Board, one containing the pow- 
dered mallein and the other sterile or saline water in quantities which will make a 5 per cent solution of mallein. The content of the bottle containing the fluid is poured into the bottle containing the mallein powder and the test solution is thus prepared. The results with this form of testing in Pennsylvania appear to be highly satisfactory, as may be seen from a publication by Dr. Meyer on the "Conjunctival reaction for glanders," in the May, 1913, number of the Journal of Infectious Diseases.

The advantages of the use of one as compared with the other of these forms of mallein for the eye test are not marked, as equally good results were obtained from the application of both forms of this product. The fact that the preparation of the raw mallein is less laborious and expensive than the mallein siccum and that it is ready for use on opening the rial would probably give this product a greater popularity. It is only natural, however, that in the event subsequent extensive testings show the superiority of the dry mallein, it will be given preference over the raw product.

METHOD OF APPLYING THE TEST.

Before the application of the ophthalmic test the animals should be (arefully examined to ascertain whether the eye shows conjunctivitis or other changes which are associated with suppuration. Should such be present the test should not be applied.

The test consists in introducing into the conjunctival sac of the eye several drops of either undiluted raw mallein or a solution of precipitated mallein ( 0.1 to 0.2 c. c. per horse). This may be introduced either with the aid of a camel's-hair brush or with an eyedropper. Only one eye is treated; the other serves as a control for comparison of the reaction. For the testing of horses in the same stable the same dropper or camel's-hair brush may be used for all the animals.

'The results of the test should be recorded as follows:

$N=$ Negative-eye unclianged.

$\mathrm{S}=$ Suspicious-seromucous discharge.

$\mathrm{P}+=$ Positive-seromucous discharge with purulent flakes.

$\mathrm{P}++=$ Positive-distinct purulent discharge.

$\mathrm{P}+++=$ Positive - purulent discharge with swelling of the eyelids.

$\mathrm{P}++++=$ Positive-strong purulent discharge with swelling and gluing together of both lids. 
The following is a copy of Q. D. Form 69, Record of Ophthalmic Mallem Test, which is used by the Bureau of Animal Industry to record all official tests:

[Obverse.]

RECORD OF OPHTHALMIC MALLEIN TEST.

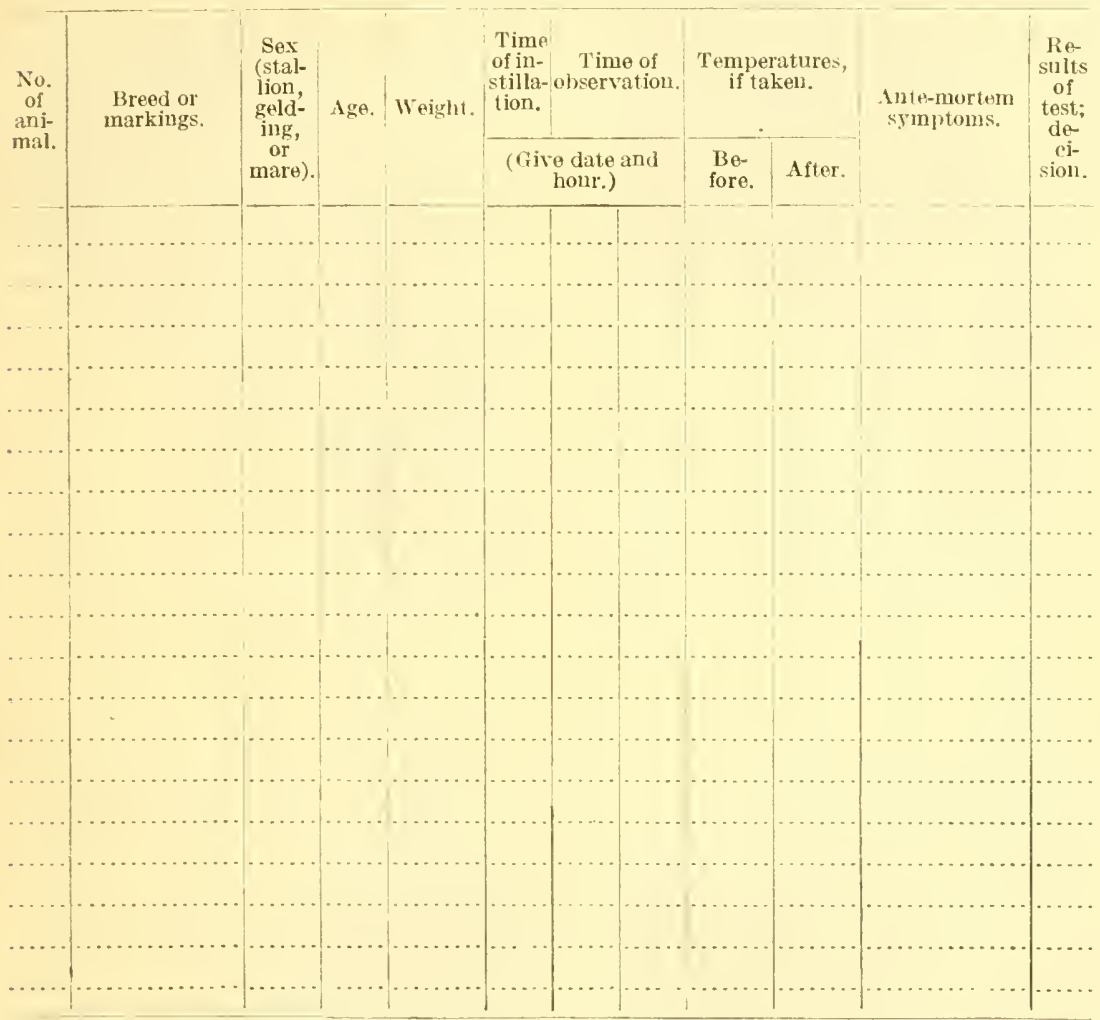

(Decision should be recorded in accorlance with results obtained, by use of: $[N]=$ Negative, eye unchanged. $[\mathrm{S}]=$ Suspieious, seromncous discharge. $[\mathrm{P}+]=$ Positive, seromucous discharge with purulent flakes. $[\mathrm{P}++]=$ Positive, distinct purulent discharge, $[\mathrm{P}+++]=$ Positive, purulent discharge with swelling of the eyelids. $\left[\mathrm{P}^{\prime}++++\right]=$ Positive, strong purulent discharge with swelling and gluing together of the lids.)

(Identify each animal by complete (leseription; if necessary use two lines for an animal.) 
RECORU OF REACTORS.

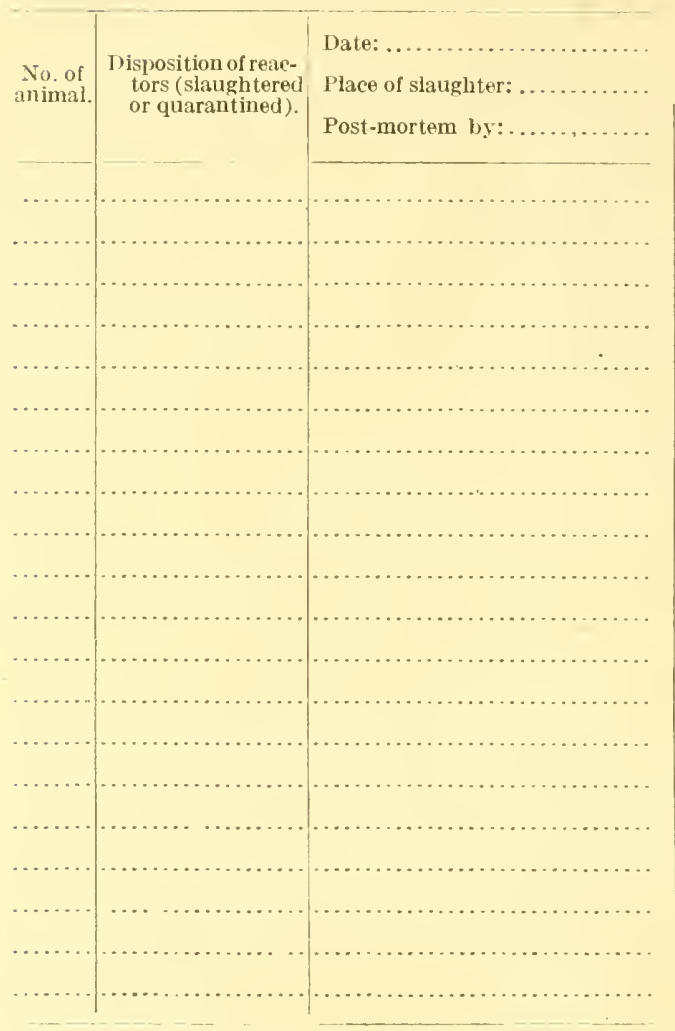

\begin{tabular}{|c|}
\hline (Q. D. Form 69.) \\
\hline $\begin{array}{l}\text { U. S. DEPARTMENT OF AGRICULTURE, } \\
\text { BUREAU OF ANIMAL INDUSTRY. }\end{array}$ \\
\hline Record of ophthalmie mallein test. \\
\hline Name of persoll making test: \\
\hline Address: ...... \\
\hline Dates: .... \\
\hline Owner: ...... \\
\hline Address: ..... \\
\hline ?....... \\
\hline Number passed: ....... \\
\hline Number reacted:....... \\
\hline Number suspicious: .......... \\
\hline Total number tested: ....... \\
\hline
\end{tabular}

EFFECT OF THE TEST ON GLANDERED AND HEALTHY ANIMALS.

As soon as the mallein is introduced into the eye practically all animals show a lacrimation, increased reddening of the conjunctiva, and slight photophobia. No significance should be given to these symptoms. They disappear in one to two hours.

Glandered animals are hypersensitive to mallein in a way that the administration of small quantities of mallein produces local inflammatory processes. In larger quantities it produces a febrile general reaction. The hypersensitiveness appears as a rule during the third week after the infection, and reaches its height in the first few monthis after the infection. In the subsequent course it may subside in retrogressive cases even to the degree observed in healthy animals, but even in these cases various conditions may bring on an increased sensibility.

The characteristic manifestations of the reaction for glanders commence as a rule in from 5 to 6 hours and last 24 to 36 hours, some- 
Bul. 166, U. S. Dept. of Agriculture

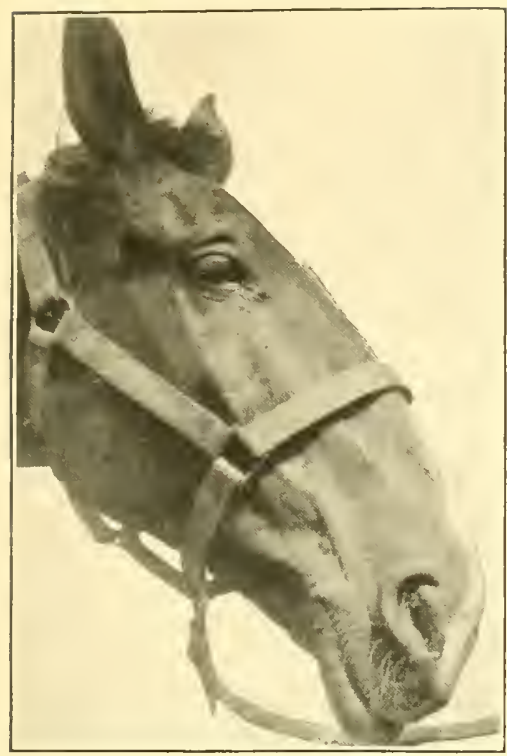

FIG. 1. $-\mathrm{P}+=$ Seromucous discharge with purulent flakes.

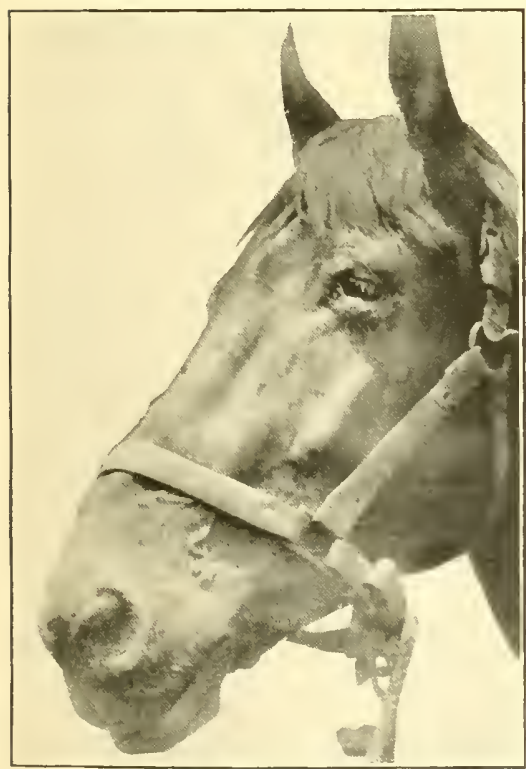

Fig. 3.-P $+++=$ Purulent discharge with swelling of the eyelids.
Plate 1.

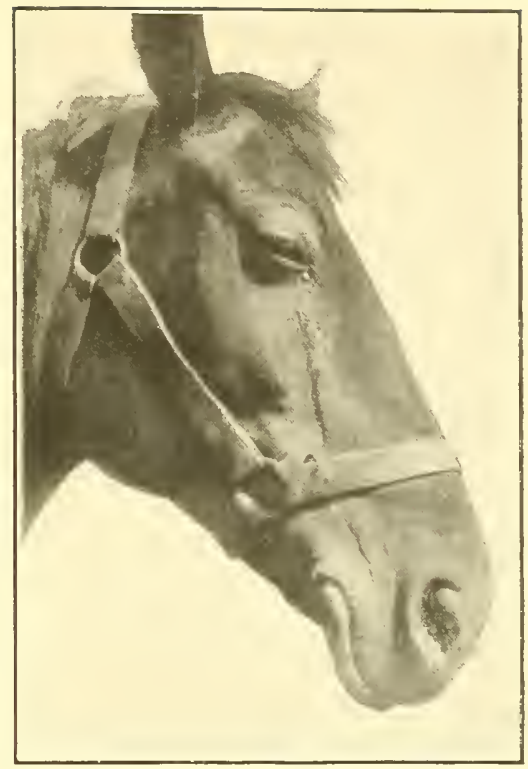

F[s, 2.-P++ - 1)istinct purulent discharge.

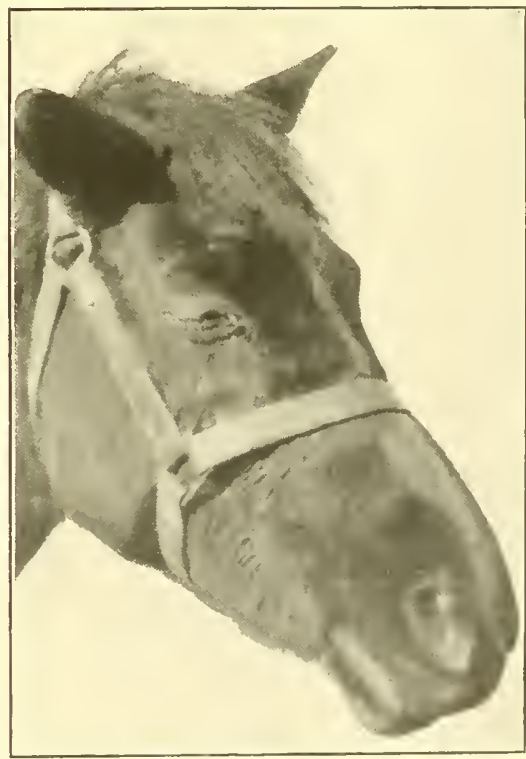

Fig, 4.-P $++++=$ Strong purulent dis"harge with swelling and gluing together of both lids. 

times longer. The reaction consists of a purulent discharge from the conjunctival sac which is typical, as well as swelling and gluing of the eyelids. It is advisable to examine the tested animals in a good light from 12 to 24 hours after the application of the test. Varying degrees of reactions are illustrated in Plate I, figures 1 to 4 .

A suppurative discharge of varying quantities is considered a positive reaction. The conjunctiva and the eycball should also be included in the examination after examining the discharge. A pseudo-reaction can be produced by artificial or accidental irritation of the eye. On the other hand the purulent discharge may have been removed (either by the stable attendant or by the animals licking each other, etc.), and the positive result thus obliterated. In such cases dried pus may be frequently found on the parts around the eye.

Generally the positive ophthalnic reactions are not accompanied by fever or systemic disturbances. Occasionally, howerer, affected horses are hypersensitive to such a degree that even the few drops of mallein placed in the eye may enter the circulation and produce fever. Therefore it is advisable, when possible, to accompany the ophthahmic reaction with temperature readings. For this purpose the temperature should be taken twice, the first time when the eye test is being made and the second time when it is judged. In a loubtful eye reaction, where there is an increased temperature of $1 \frac{1}{2}$ degrees F., the test should be considered positive if the animal had a normal temperature at the time the test was made. As stated before, it should be remembered that the intensity of the reaction has no relation to the extent of the disease in the animal tested.

In the absence of any secretion the test should be considered negative. When there is a mucous secretion or larrimation during the period of reaction the test must be considered as atypical, and in such cases it may be repeated the same day, when, as a rule, the results are more confirming.

The application of the ophthalmic test should not be repeated more than three times on the same animal within three months, as experiments show that the reaction after the third application within this short period usually loses its intensity in positive cases, and on subsequent tests may be entirely absent. In cases where the results of the second test immediately following the first test are atypical, the blood of such animal may be drawn and forwarded to a laboratory for the serum diagnosis. From experience gained with the ere test such a procedure would become necessary only in a comparatively few cases. In the control of glanders, animals may be retested every six months with satisfactory results. 


\section{REPORT OF THE AMERICAN VETERINARY MEDICAL ASSOCIATION ON THE OPHTHALMIC TEST.}

The special committec on the control of glanders of the American Veterinary Medical Association has issued a most excellent report on the varions phases of diagnosis of glanders. The conclusions on the value of the cye test offered by this committee are in perfect accord with our findings, we therefore deem it advisable to include them in this paper, as follows:

1. The ophthalmic test not ouly meets all the requirements, but is without doulst the most convenient diagnostic method at our command.

2. Its reliability compares favorably with any of the other tests available.

3. The reaction is usually very distinct, and doubtful or atypical reactions are rather infrequent.

4. The ophthalmic tesi has the advantage that it does not interfere with subsecuent serum or other mallein tests if such are deemed necessary.

5. The test may be repeated within 24 hours on same or control eye. If another retest is necessary, it should not be made in less than three weeks.

6. The ophtholmir test slould be recognized by State and Federal authorities, since its reliability can no longer be doubted.

7. In all atypical and doubtful cases of the ophthalmic test, the combuned complement-fixation and agglutination or subeutaneous mallein test should be utilized for "onfirmation. Such a procedure would minimize the failure and would assure the hest results in the control of the disease in a single stable or in an entire community.

\section{CONCLUSION.}

The results achieved in Austria with the ophthalmic test have been remarkably successful and deserve the most carnest consideration. The report of Prof. Schmurer on The Results of the Diagnostic Procedure in Glanders in Austria is a convincing proof as to the value of the eye test in the control of glanders. The senior writer received a communication only a short tme ago from Prof. Schnurer, and since it deals principally with the diagnostic value of the eye test, a quotation from the letter will no doubt be permissible:

I am at the present contemplating collecting the results of the eradication of glanders in Austria during the last three years (1910-1912). During this time 60,894 testw were undertaken on 47,973 horses. Of 272 cases which were found on post-mortem to he affected with glanders 240 ( 88.2 per cent) were positive, 21 ( 7.7 per s'ent) gave an atypical reaction, while 11 (4 per cent) were negative. Of the 47,701 healthy horses, $189(0.39$ per cent) were positive or atypical, the remaining 47.512 (99.61 per cent) gave a negative reaction.

Aceording to these results. therelore, the eradication of glanders is only a question of organization-that is, the malleinization of hores at the border and conscientions following up of all suspected horses. Such procedure would, without doubt, result in a complete "ratication of glanders. At the Veterinary School of Austria we now have difficuly in showing the student cases of glanders, and for demonstration purposes we are compelled to infect horses artificially, whereas several years ago we lad every week at least one case of glanders in our rlinirs.

1 use as mallein at the present time a product which 1, myself, prepare. which represents a bouillen filtrate from seven different strains of glanders bacilli which has been concentrated to one-tenth of the original volume 
The optinistic view of Prof. Schnurer is certainly justificd from the results he achieved, and clearly shows that with proper organization in the control work of glanders the eradication of the discase is only a question of time.

The eradication of outbreaks of glanders can not, of course, be altogether attributed to the eye test, since from the report of Nevermann, reterinary councilor of Prussia, glanders has diminished remarkably in that country, where they employ the rombined complement-fixation and agghtutintion test for the diagnosis, while Megilvara has practically eradicated glanders from the Provinee of Manitoba by means of the subcutaneous maltein test. The method of testing by neans of complement-fixation and agglutination is undoubtedly the most aceurate of any arailable, but since it "an not be as conveniently applied as the eye test, its disadvantages are apprarent. There is no doubt that with the applieation of either the eye test or the combined complement-fixation and agglutination tests, equally good results may be obtained provided that the work is conscientiously carried out and that all the reactors are destroyed without hesitation.

As long as the anthorities will limit themselves to the destruction of clinical cases only and will not take immediate action on reartors of the occult and latent character, glanders will not only continne to exist, but it will spread. 
